\title{
Hydrothermal Preparation, Crystal Structure, Photoluminescence and UV-Visible Diffuse Reflectance Spectroscopic Properties of a Novel Mononuclear Zinc Complex
}

\author{
Xiu-Guang Yi, ${ }^{1, \star}$ Xiao-Niu Fang, ${ }^{1}$ Jin Guo, ${ }^{1} \mathrm{Jia}^{\mathrm{Li}}{ }^{1,3}$ and Zhen-Ping $\mathrm{Xie}^{2}$ \\ ${ }^{1}$ School of Chemistry and Chemical Engineering, Jinggangshan University, Institute of Applied Chemistry, \\ Jian Jiangxi 343009, China \\ 2 Jian Academy of Forestry Sciences, Jian Jiangxi 343009, China \\ ${ }^{3}$ State Key Laboratory of Molecular Reaction Dynamics, Dalian Institute of Chemical Physics, \\ Chinese Academy of Sciences, Dalian 116023, China \\ * Corresponding author: E-mail: jayxgggchem@163.com \\ Tel: +86(796)8100490; fax: +86(796)8100490
}

Received: 08-29-2019

\begin{abstract}
A novel mononuclear zinc complex $\left[\mathrm{ZnL}(\mathrm{Phen})\left(\mathrm{H}_{2} \mathrm{O}\right)\right] \cdot \mathrm{H}_{2} \mathrm{O}$ containing the mixed ligands of Phen $(\mathrm{Phen}=1,10$-phenanthroline) and 3-hydroxy-2-methylquinoline-4-carboxylic acid (HL) was prepared by hydrothermal synthesis and its crystal structure was characterized by X-ray single-crystal diffraction method. The title complex crystallizes in the orthorhombic systems and forms monomeric units. The molecules in the title complex are connected through the interactions of hydrogen-bonding and $\pi \cdots \pi$ interactions to give a three-dimensional $(3 D)$ supramolecular structure. The fluorescence result discovers a wide emission band in the violet blue region. Time-dependent density functional theory (TDDFT) calculations reveal that this emission can be attributed to ligand-to-ligand charge transfer (LLCT). Solid-state diffuse reflectance shows there is a wide optical band gap.
\end{abstract}

Keywords: Hydrothermal preparation; photoluminescence; band gap; zinc.

\section{Introduction}

In recent years, metal complexes have attracted increased attention due to their numerous properties, as well as their potential application in the fields of catalysis, medicine, photoluminescence, semiconductor materials, and so on. ${ }^{1-4}$ So far, researchers have been engaged in a large number of studies on the properties of lanthanide and transition metal complexes. ${ }^{5-7}$ In these characteristics, photoluminescence is particularly attractive to us. The interesting photoluminescence properties of transition metal complexes mainly come from the $d^{10}$ orbital electron configuration in transition metal elements. As far as we know, as long as the $d^{10}$ electrons of transition metals can be excited effectively, zinc complexes usually exhibit strong photoluminescence. Up to date, extended research affords have been devoted to the design, preparation and characterization of novel transition photolumines-

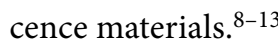

Despite of a large number of studies on photoluminescence properties, semiconductor properties of zinc complexes have rarely been reported. ${ }^{14-17}$ Semiconductor materials are attractive because they are potential photocatalysts for helping to solve some of the environmental problems of the $21^{\text {th }}$ century. So far, some transition metal-organic semiconductor complexes have been documented, such as, $\left[\mathrm{Ln}(\mathrm{IA})_{3}\left(\mathrm{H}_{2} \mathrm{O}\right)_{2}\right]_{\mathrm{n}}\left(\mathrm{Hg}_{3} \mathrm{Cl}_{9}\right)_{\mathrm{n}} 4 \mathrm{n}\left(\mathrm{H}_{2} \mathrm{O}\right)$, (IA = isonicotinic acid $),{ }^{18} \mathrm{Zn}\left(\mathrm{O}_{2} \mathrm{CCH}_{3}\right)_{2}\left(\mathrm{H}_{2} \mathrm{O}\right)_{2},{ }^{19} \mathrm{NiL}_{2}(\mathrm{~L}=$ 2-ethoxy-6-(N-methyliminomethyl)phenolate). ${ }^{20}$ As the result, transition metal-organic semiconductor complexes are worthy to exploring.

In order to synthesize metal coordination compounds, it is crucial to consider appropriate organic ligands 
since the composition of organic ligands can determine the crystal structure and function of metal complexes. Many organic ligands, such as aromatic sulfonic acid, aromatic carboxylic acid and $\mathrm{N}$-heterocyclic derivatives, ${ }^{21,22}$ are used in the preparation of metal complexes. Hydroxyquinoline carboxylic acid is an interesting organic ligand with multiple bonding sites, which contains not only phenolic hydroxyl group, carboxyl group, but also nitrogen atom. As a wellknown rigid and rod-like molecule, 1,10-phenanthroline (Phen) is an interesting secondary building unit (SBU) for the construction of a supramolecular or an extended structural motif, because Phen possesses a delocalized $\pi$-electron system, which allows it to be a useful candidate in preparing new fluorescence compounds with potential applications.

Based on this, we are interested in the crystal engineering of $\mathrm{Zn}$ (II) complexes with 3-hydroxy-2-methylquinoline-4-carboxylic acid (HL) and Phen as the mixed ligands. In this article, we report the hydrothermal synthesis, X-ray crystal structure, photoluminescent and UV-visible diffuse reflectance spectroscopic properties, as well as time-dependent density functional theory (TDDFT) calculations for the novel zinc(II) complex, $\left[\mathrm{ZnL}(\right.$ Phen $\left.)\left(\mathrm{H}_{2} \mathrm{O}\right)\right] \cdot \mathrm{H}_{2} \mathrm{O}$, (Phen $=1,10$-phenanthroline, $\mathrm{HL}=3$-hydroxy-2-methylquinoline-4-carboxylic acid), with a mononuclear structure.

\section{Experimental}

\section{1. Materials and Instrumentation}

The reagents and chemicals for the synthesis of the title compound were analytical reagent grade, commercially available and applied without further purification. Infrared spectra were recorded in the Nicolet iS10 spectrometer using $\mathrm{KBr}$ pellets. The photoluminescence study with solid state samples was performed on the FX-97XP fluorescence spectrometer. The solid state UV/Vis diffuse reflectance spectroscopy was carried out TU-1901 UV/Vis spectrometer with an integrating sphere in the wavelength range of $190-900 \mathrm{~nm} . \mathrm{BaSO}_{4}$ power was used as a reference, on which the finely ground powder sample was coated as a $100 \%$ reflectance. ${ }^{1} \mathrm{H}$ NMR spectra were measured on Bruker Avance $400 \mathrm{MHz}$ instrument with dimethyl sulfoxide (DMSO) as solvent. TDDFT investigations were carried out by means of the Gaussian 09 suite of program packages.

\section{2. Synthesis of 3-hydroxy-2- methylquinoline-4-carboxylic acid (HL)}

Synthesis of isatin: indigo ( $131 \mathrm{~g}, 0.5 \mathrm{~mol}), \mathrm{K}_{2} \mathrm{Cr}_{2} \mathrm{O}_{7}$ $(74 \mathrm{~g}, 1.0 \mathrm{~mol})$ and distilled water $(200 \mathrm{~mL})$ were added into the flask with three necks of $500 \mathrm{~mL}$ and stirred. After cooling, dilute $\mathrm{H}_{2} \mathrm{SO}_{4}(10 \%, 250 \mathrm{~mL})$ was added and kept stirring at $43^{\circ} \mathrm{C}$ for $1.5 \mathrm{~h}$. The mixture was diluted with twice its volume of distilled water, filtered off, dissolved in $10 \%$ $\mathrm{NaOH}$ solution, filtered again and neutralized with $10 \% \mathrm{HCl}$ to $\mathrm{pH}=7$. Yield: $116 \mathrm{~g}(90 \%)$; m.p. $210^{\circ} \mathrm{C}$; HRMS $m / z$ (ESI): calcd. for $\mathrm{C}_{8} \mathrm{H}_{5} \mathrm{NO}_{2}\left([\mathrm{M}+\mathrm{H}]^{+} 147.0320\right.$, found 147.0826.

Synthesis of HL: isatin (73.5 g, $0.5 \mathrm{~mol})$ and $\mathrm{NaOH}$ $(20 \mathrm{~g}, 0.5 \mathrm{~mol})$ were dissolved in distilled water $(200 \mathrm{~mL})$ and filtered. The filtrate and $\mathrm{NaOH}(20 \mathrm{~g}, 0.5 \mathrm{~mol})$ were added into chloroacetone (92 g, $1.0 \mathrm{~mol}$ ), and hydrochloric acid was added dropwise to adjust $\mathrm{pH}=7$, and then the mixture was filtered. Yield: $96 \mathrm{~g}$ (95\%); m.p. $225^{\circ} \mathrm{C}$; HRMS $m / z$ (ESI): calcd. for $\mathrm{C}_{11} \mathrm{H}_{9} \mathrm{NO}_{3}\left([\mathrm{M}+\mathrm{H}]^{+} 203.0582\right.$, found 203.0548. ${ }^{1} \mathrm{H}$ NMR $(400 \mathrm{MHz}, \mathrm{DMSO}) \delta 9.15(\mathrm{~s}, 1 \mathrm{H}), 7.93$ $(\mathrm{d}, J=8.0 \mathrm{~Hz}, 1 \mathrm{H}), 7.64(\mathrm{t}, J=8.0 \mathrm{~Hz}, 1 \mathrm{H}), 7.60-7.52(\mathrm{~m}$, $2 \mathrm{H}), 2.70(\mathrm{~s}, 3 \mathrm{H})$.

\section{3. Synthesis of $\left[\mathrm{ZnL}(\mathrm{Phen})\left(\mathrm{H}_{2} \mathrm{O}\right)\right] \cdot\left(\mathrm{H}_{2} \mathrm{O}\right)$}

The title compound was prepared by mixing $\mathrm{Zn}\left(\mathrm{CH}_{3}\right.$ $\mathrm{COO})_{2} \cdot 2 \mathrm{H}_{2} \mathrm{O}(1.0 \mathrm{mmol}, 219.5 \mathrm{mg})$, HL $(1.0 \mathrm{mmol}, 203$ $\mathrm{mg}$ ), Phen (1.0 mmol, $180 \mathrm{mg}), 1 \mathrm{~mL}$ triethylamine and 10 $\mathrm{mL}$ distilled water in a $25 \mathrm{~mL}$ Teflon lined stainless steel autoclave. The mixture was heated to $120^{\circ} \mathrm{C}$ and kept at this temperature for 7 days. When the mixture was cooled slowly down to room temperature, yellow crystals suitable for X-ray analysis were collected and washed. Yield $411 \mathrm{mg}$ (85\% based on zinc). IR ( $\left.\mathrm{KBr}, \mathrm{cm}^{-1}\right)$ : 3424(vs), 1624(w), 1580(w), 1518(m), 1483(s), 1446(m), 1351(vs), 1320(s), 851(vs), 821(w), 773(w), 726(s); Anal. Calcd for $\mathrm{C}_{23} \mathrm{H}-$ ${ }_{19} \mathrm{~N}_{3} \mathrm{O}_{5} \mathrm{Zn}: \mathrm{C}, 57.22 ; \mathrm{H}, 3.97 ; \mathrm{N}, 8.70$; found: $\mathrm{C}, 57.30 ; \mathrm{H}$, $3.95 ; \mathrm{N}, 8.75 \%$.

\section{4. Crystal Structure Determination}

The single crystal X-ray diffraction data of the title complex was collected on a SuperNova CCD X-ray diffrac-

Table 1. Crystal data and structure refinement details for the title complex

\begin{tabular}{ll}
\hline Formula & $\mathbf{C}_{23} \mathbf{H}_{19} \mathbf{N}_{\mathbf{3}} \mathbf{O}_{5} \mathbf{Z n}$ \\
\hline$F w$ & 482.78 \\
Color & yellow \\
Crystal system & orthorhombic \\
Space group & Pbca \\
$a(\AA)$ & $9.5869(3)$ \\
$b(\AA)$ & $18.6505(7)$ \\
$c(\AA)$ & $23.2010(9)$ \\
$V\left(\AA^{3}\right)$ & $4148.3(3)$ \\
$Z$ & 8 \\
Reflections collected & 12374 \\
Independent, observed & \\
Reflections $\left(R_{\text {int }}\right)$ & $4878(0.0212)$ \\
$d_{\text {calcd. }}\left(\mathrm{g} / \mathrm{cm}^{3}\right)$ & 1.546 \\
$\mu\left(\mathrm{mm}^{-1}\right)$ & 1.226 \\
$T(\mathrm{~K})$ & $293(2)$ \\
$F(000)$ & 1984 \\
$R_{1}, w R_{2}$ & $0.0353,0.083$ \\
$S$ & 1.04 \\
$\Delta \rho\left(\mathrm{max}^{2}, \min \right)\left(\mathrm{e} / \AA^{3}\right)$ & $0.29,-0.40$ \\
\hline
\end{tabular}


tometer with graphite monochromated Mo- $K \alpha$ radiation $(\lambda=0.71073 \AA)$ by means of a $\omega$ scan method. The data reduction and empirical absorption corrections were performed with CrystalClear software. ${ }^{24}$ Using Olex $2,{ }^{25}$ the structure for the title complex was solved with the ShelXT, ${ }^{26}$ the structure solution program using Intrinsic Phasing and refined with the ShelXL refinement package using Least Squares minimization. ${ }^{27}$ All of the non-hydrogen atoms and the hydrogen atoms of water were generated based on the subsequent Fourier difference maps and refined anisotropically. The other hydrogen atoms were located theoretically and ride on their parent atoms. Crystallographic data and structural refinements for the title complex are summarized in Table $\mathbf{1}$. Selected bond lengths and bond angles for the crystal structure are displayed in Table 2. The hydrogen bonding interactions are presented in Table 3.

\section{Results and Discussion}

\section{1. Preparation of Ligand and the Title Complex}

The ligand HL was prepared according to the literature, ${ }^{23}$ as shown in Scheme 1. At the first, indigo was oxidized by potassium dichromate to form the intermediate isatin. Then the isatin is hydrolyzed, cyclized by nucleophilic addition, and finally dehydrated to form the ligand, 3-hydroxy-2-methylquinoline-4-carboxylic acid. Finally, the title complex was prepared by hydrothermal synthesis of the ligand with zinc acetate, phenanthrene and water in the presence of triethylamine. By the infrared spectrum of the title complex, the strong broad band at $3424 \mathrm{~cm}^{-1}$ indicates the presence of water, the absorption at $1624 \mathrm{~cm}^{-1}$ was assigned to the contribution of $\mathrm{C}=\mathrm{N}$, the absorptions at $1580 \mathrm{~cm}^{-1}$ and $1351 \mathrm{~cm}^{-1}$ are regarded as the presence of monodentated carboxylate in the title complex.

\section{2. Structural Description}

Single crystal X-ray diffraction analysis reveals that the title complex is a neutral molecule and it crystallizes in the space group $\mathrm{Pbca}$ of the orthorhombic system. The $\mathrm{Zn}^{2+}$ ion is sitting at the inversion center and is pentacoordinated by the HL, Phen and water molecule, yielding a rectangular pyramid geometry. The $\mathrm{Zn}^{2+}$ ion is coordinat- ed by three oxygen atoms and two nitrogen atoms, of which two oxygen atoms are from HL ligand, one oxygen atom is from coordinated water molecule, two nitrogen atoms are from Phen ligand. Quinolinecarboxylate $\left(\mathrm{L}^{-}\right)$ and Phen act as the bidentate ligand, water molecule acts as the monodentate ligand coordinated to the zinc metal center, as presented in Fig. 1. The bond distance of $\mathrm{Zn1-}$ $\mathrm{O} 2$ is $2.013(2) \AA, \mathrm{Zn} 1-\mathrm{O} 3$ is $1.932(2) \AA, \mathrm{Zn} 1-\mathrm{O} 4$ is $1.988(2) \AA$, while that $\mathrm{Zn} 1-\mathrm{N} 1$ is $2.105(2) \AA, \mathrm{Zn} 1-\mathrm{N} 2$ is 2.193(2) $\AA$. These are comparable with that reported in the references. ${ }^{28-30} \mathrm{~A}$ intramolecular hydrogen bond can be found between the $\mathrm{C}-\mathrm{H}$ bond and carbonyl oxygen atom (C8-H8...O1). A lots of intermolecular hydrogen bonds can be found in the crystal structure form $\mathrm{O}-\mathrm{H} \cdots \mathrm{O}$ or $\mathrm{O}-\mathrm{H} \cdots \mathrm{N}$, such as $\mathrm{O} 4-\mathrm{H} 4 \mathrm{~A} \cdots \mathrm{O} 1^{\mathrm{i}}$ (Symmetry code (i): $1 / 2+$

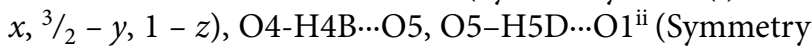
code (ii): $1+x, y, z)$, O5-H5E $\cdots \mathrm{N} 3^{\text {iii }}$ (Symmetry code (iii): $1 / 2+x, y, 1 / 2-z)$, and thus formed a three-dimensional supramolecular structure, as presented in Fig. 2. and Fig. 3. Additionally, there are abundant offset face-to-face $\pi \cdots \pi$ stacking interaction between $C g 2 \cdots C g 5^{\text {iv }}, C g g 1 \cdots C g 5^{\mathrm{v}}$, $C g 4 \cdots C g 3^{\text {vi }}$ (Symmetry codes (iv): $2-x, 1-y, 1-z$; v: $1-x$, $1-y, 1-z$; (vi): $-1 / 2+x, y, 1 / 2-z$ ), as present in Fig. 4 (The $\mathrm{Cg} 1$ is ring of N1-C19-C20-C21-C22-C23, Cg2 is N2-C12C13-C14-C15-C16, Cg3 is N3-C2-C3-C4-C6-C7, Cg4 is $\mathrm{C} 6$ to $\mathrm{C} 11$ and $\mathrm{Cg} 5$ is $\mathrm{C} 15$ to $\mathrm{C} 20)$. The centroid-centroid distance of $C g 2 \cdots C g 5^{\text {iv }}$ is $3.753(2) \AA$, with the slippage distance $1.290 \AA$ and the dihedral angle of $0.5(2)^{\circ}$, for the $C g 1 \cdots C g 5^{\mathrm{v}}$ is $3.767(2) \AA, 1.637 \AA$ and $1.9(2)^{\circ}$; for the $C g 4 \cdots C g 3^{\mathrm{vi}}$ is 3.883(2) $\AA$, $1.436 \AA$ and 3.6(2) .

Table 2. Selected bond lengths $(\AA)$ and bond angles $\left({ }^{\circ}\right)$

\begin{tabular}{cccc}
\hline Distance & $(\AA)$ & Distance & $(\AA)$ \\
\hline Zn1-O3 & $1.932(2)$ & Zn1-N1 & $2.105(2)$ \\
Zn1-O4 & $1.988(2)$ & Zn1-N2 & $2.193(2)$ \\
Zn1-O2 & $2.013(2)$ & & \\
\hline Angle & $\left(^{\circ}\right)$ & Angle & $\left(^{\circ}\right)$ \\
\hline O3-Zn1-O4 & $122.76(7)$ & O2-Zn1-N2 & $169.03(7)$ \\
O3-Zn1-O2 & $90.11(6)$ & N1-Zn1-N2 & $77.48(7)$ \\
O4-Zn1-O2 & $93.91(7)$ & C1-O2-Zn1 & $128.2(2)$ \\
O3-Zn1-N1 & $126.71(7)$ & C3-O3-Zn1 & $125.0(2)$ \\
O4-Zn1-N1 & $109.73(7)$ & C23-N1-Zn1 & $126.5(2)$ \\
O2-Zn1-N1 & $95.21(7)$ & C20-N1-Zn1 & $115.1(2)$ \\
O3-Zn1-N2 & $87.85(6)$ & C12-N2-Zn1 & $128.6(2)$ \\
O4-Zn1-N2 & $96.25(7)$ & C16-N2-Zn1 & $112.5(2)$ \\
\hline
\end{tabular}<smiles>O=C1C(=C2Nc3ccccc3C2=O)Nc2ccccc21</smiles>

Indigo

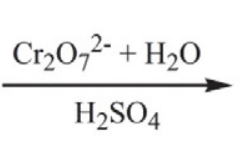

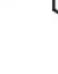<smiles>O=C1Nc2ccccc2C1=O</smiles>

Isatin<smiles>CC(=O)OC1CCCCCOC1=O</smiles>

$\mathrm{HL}$

Scheme 1: Synthetic route of ligand HL 
Table 3. Hydrogen bonds for the title complex

\begin{tabular}{llllc}
\hline$D-\mathrm{H} \cdots A$ & $D-\mathrm{H}, \AA$ & $\mathrm{H} \cdots A, \AA$ & $D \cdots A, \AA$ & $D-\mathrm{H} \cdots A,{ }^{\circ}$ \\
\hline $\mathrm{O}^{\circ}-\mathrm{H} 4 \mathrm{~A} \cdots \mathrm{O} 1^{\mathrm{i}}$ & $0.76(3)$ & $1.96(3)$ & $2.716(2)$ & $171(3)$ \\
$\mathrm{C} 8-\mathrm{H} 8 \cdots \mathrm{O} 1$ & 0.93 & 2.26 & $2.852(3)$ & 120.6 \\
${\text { O5-H5D } \cdots \mathrm{O} 1^{\mathrm{ii}}}_{\mathrm{O} 5-\mathrm{H} 5 \mathrm{E} \cdots \mathrm{O} 1^{\mathrm{iii}}}$ & $0.86(3)$ & $1.95(3)$ & $2.787(3)$ & $163(3)$ \\
$\mathrm{O} 4-\mathrm{H} 4 \mathrm{~B} \cdots \mathrm{O} 1$ & $0.80(3)$ & $1.95(3)$ & $2.825(3)$ & $170(3)$ \\
\hline
\end{tabular}

Symmetry codes: (i) $1 / 2+x, 3 / 2-y, 1-z$; (ii) $1+x, y, z$; (iii) $1 / 2+x, y, 1 / 2-z$.

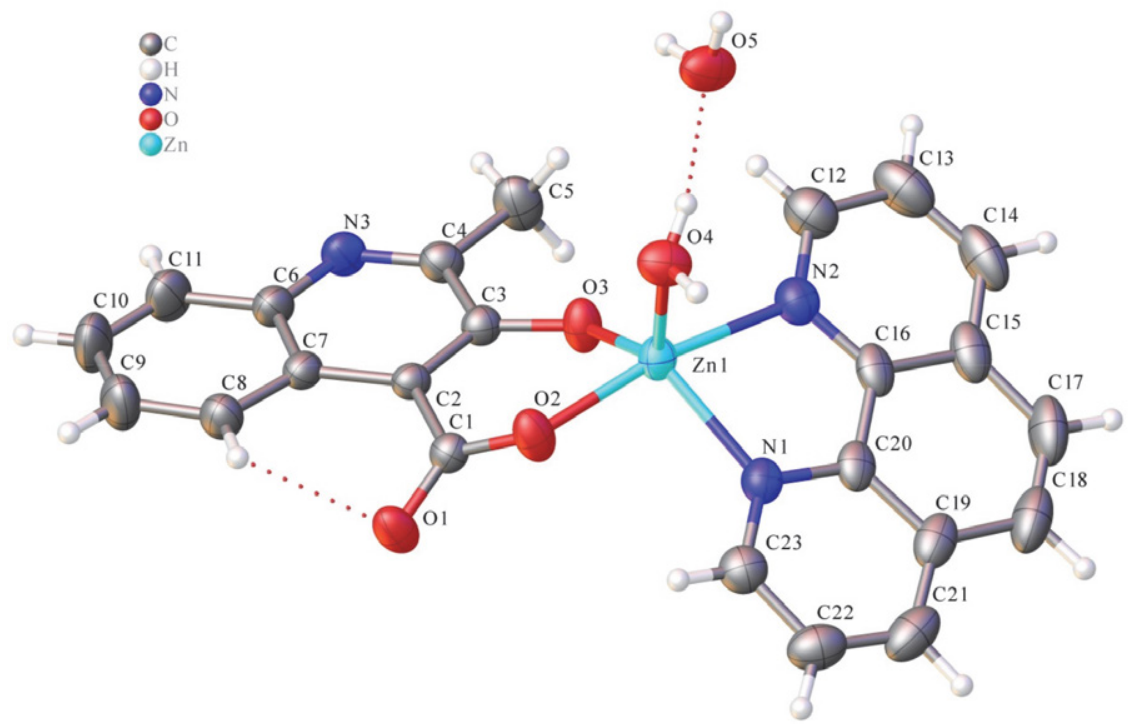

Fig. 1. The molecular structure of the title complex

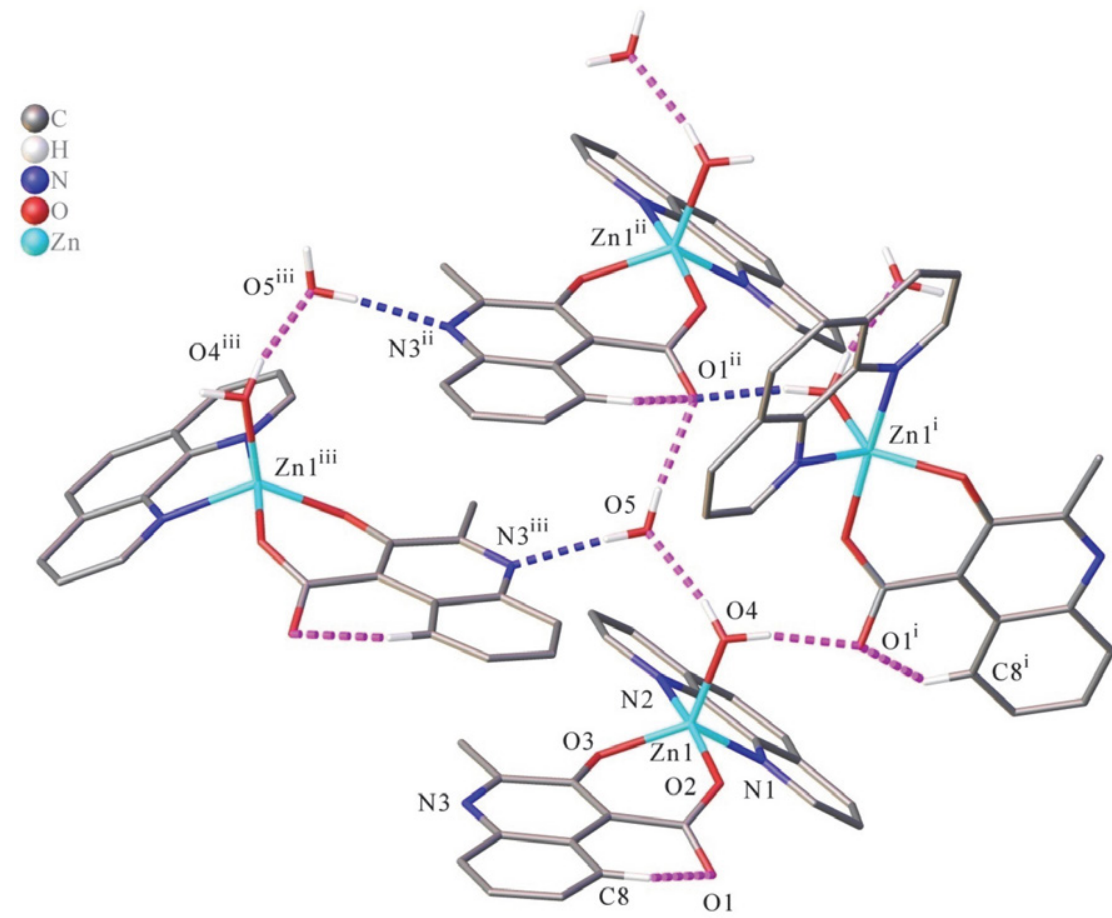

Fig. 2. The hydrogen bonds of the title complex. Hydrogen atoms not involved in the motif shown were removed for clarity. Symmetry codes: (i) $1 / 2$ $+x, 3 / 2-y, 1-z$; (ii) $1+x, y, z$; (iii) $\frac{1}{2}+x, y, 1 / 2-z$. 

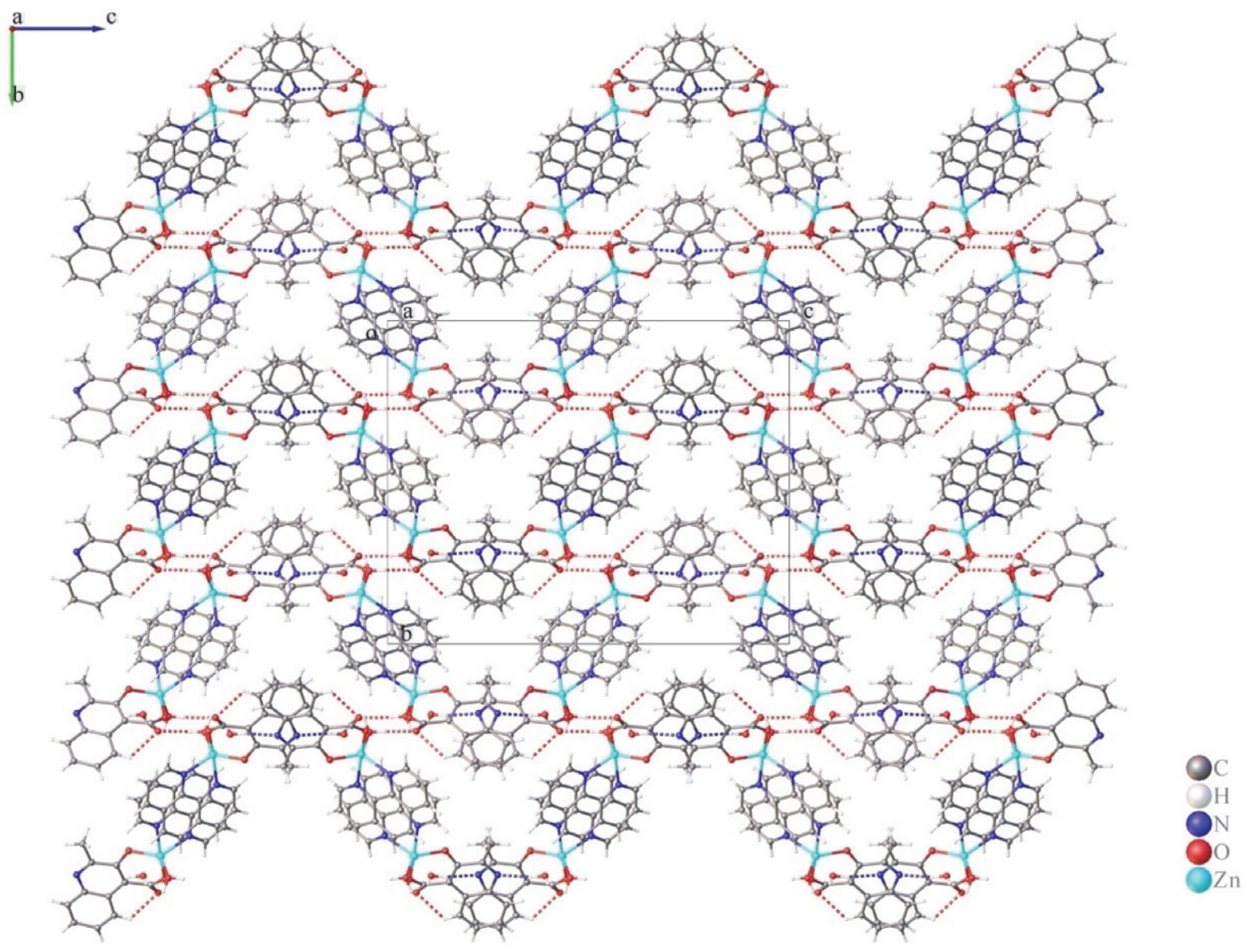

Fig. 3. The packing diagram of the title complex with the dashed lines representing the hydrogen bonding interactions. Symmetric code: (i) $1 / 2+x$, $3 / 2-y, 1-z$; (ii) $1+x, y, z$; (iii) $1 / 2+x, y, 1 / 2-z$.

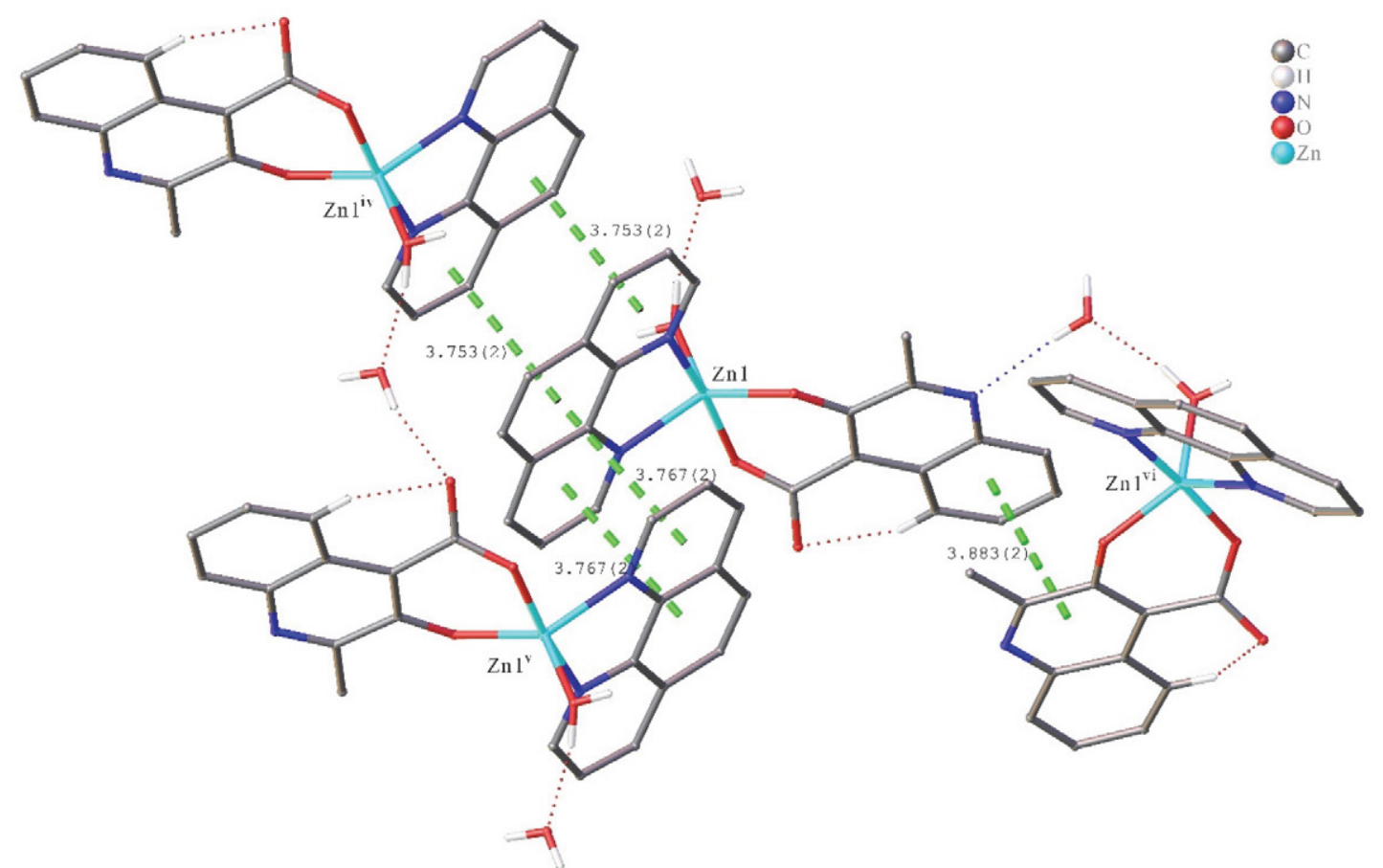

Fig. 4. The $\pi \cdots \pi$ stacking interactions of the title complex. Symmetric codes (iv): $2-x, 1-y, 1-z ;(\mathrm{v}): 1-x, 1-y, 1-z ;(\mathrm{vi}):-1 / 2+x, y, 1 / 2-z$. 


\section{2. Photoluminescence}

In recent years, the photoluminescence of coordination compounds has gained increasing interest. ${ }^{31-33} \mathrm{Gen}-$ erally, coordination compounds containing lanthanide and transition elements can exhibit photoluminescence behavior because they possess rich $4 f$-orbit and $3 / 4 d$-orbit electron configurations. Many studies about the photoluminescence performance of lanthanide and transition compounds have been conducted so far. ${ }^{34,35}$ The title complex contains $\mathrm{Zn}^{2+}$ ions, therefore, we deemed that zinc and HL complexes can possibly exhibit interesting photo-

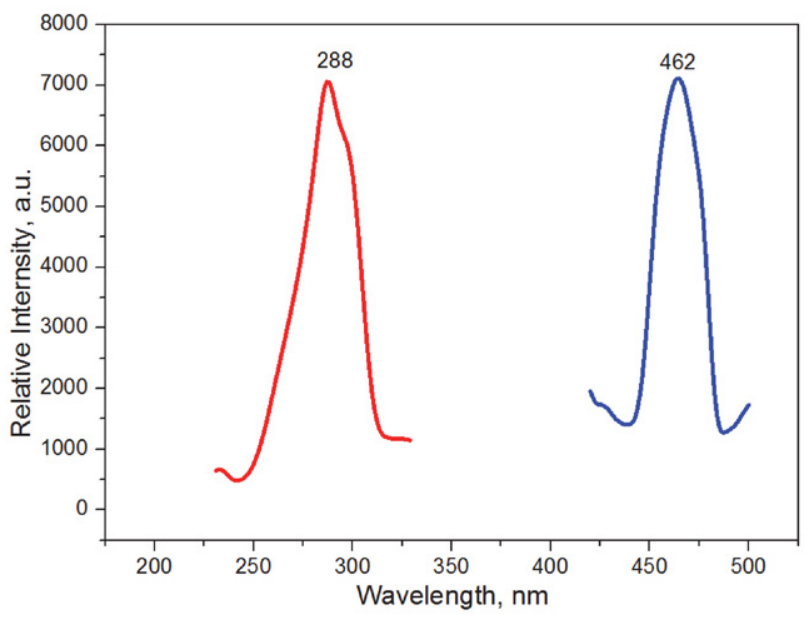

Fig. 5. The solid-state excitation (red) and emission (blue) spectra of the title complex at room temperature (color figure available online)

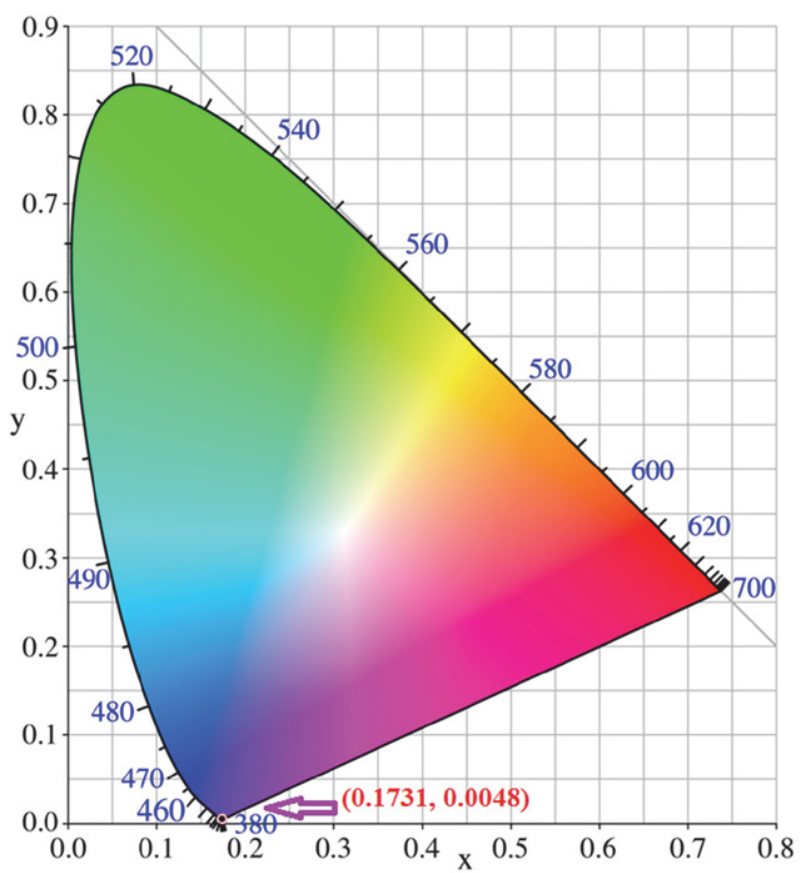

Fig. 6. CIE chromaticity diagram and chromaticity coordinates of the emission spectrum of the title complex luminescence performance. Based on the above considerations and in order to reveal its potential photoluminescent properties, we carried out the photoluminescence spectra with solid state samples at room temperature and the result is presented in Fig. 5. It is obvious that the photoluminescent spectrum of the title complex displays an effective energy absorption residing in the wavelength range 240-325 $\mathrm{nm}$. Upon the emission of $462 \mathrm{~nm}$, the excitation spectrum shows a band at $288 \mathrm{~nm}$. We further measured the corresponding photoluminescence emission spectrum of the title compound. Upon excitation at 288 $\mathrm{nm}$, the emission spectrum is characterized by a sharp band at $462 \mathrm{~nm}$ in the blue purple region of the spectrum. The emission band of the title complex is located in the blue purple light region with the CIE (Commission Internationale de I'Éclairage) chromaticity coordinate $(0.1731$, 0.0048) (Fig. 6), As a result, the title complex is a potential blue purple photoluminescent material.

\section{3. TDDFT Calculations}

In order to investigate the fluorescence essentiality of the title complex, we performed its theoretical calculation in light of the time-dependent density functional theory (TDDFT) based on the B3LYP function with basis set of SDD for $\mathrm{Zn}$ and $6-31 \mathrm{G}^{\star}$ for $\mathrm{C}, \mathrm{H}, \mathrm{O}, \mathrm{N}$ and carried out by means of the Gaussian09 program. ${ }^{36-38}$ The ground state geometry was truncated from its single crystal X-ray data (without optimization). The characteristics of the highest occupied molecular orbital (HOMO) and the lowest unoc-

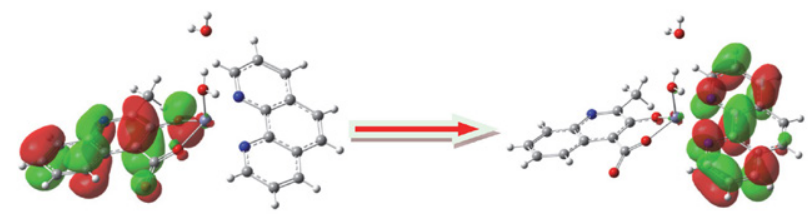

(a) HOMO

(b) LUMO

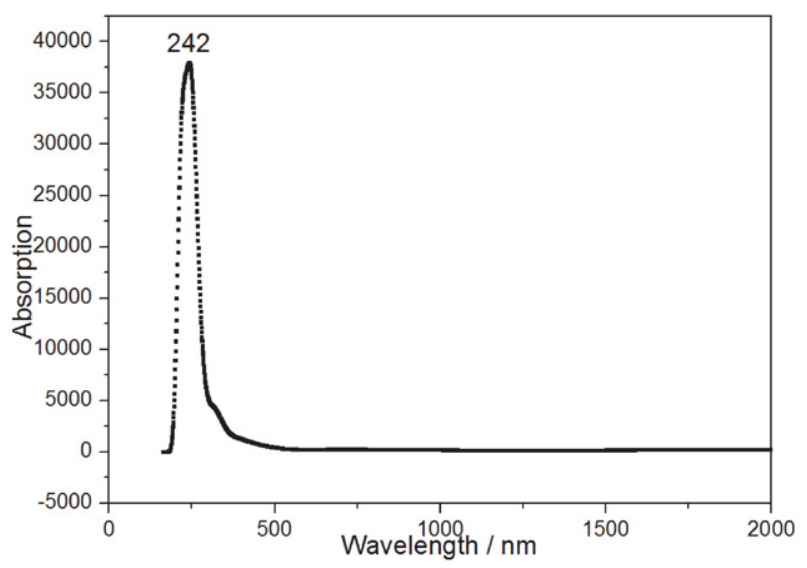

(c) Simulated fluorescent emission spectra

Fig. 7. (a) HOMO and (b) LUMO (with isosurface of 0.003) and TD-DFT simulated fluorescent emission spectra of the title complex 
cupied molecular orbital (LUMO) as well as simulated fluorescent emission spectra of the title complex are given in Fig. 7. It is easy to find out that the electron population of the singlet state of HOMO is dominantly located at the HL ligand with an energy of -0.14331 Hartree. However, the electron density of the LUMO is largely distributed on the Phen ligand with an energy of -0.10413 Hartree. The energy difference between LUMO and HOMO is 0.03918 Hartree, and this is small enough to allow the charge transfer from HOMO to LUMO. In light of this observation, it is proposed that the essence of the photoluminescence of the title complex could be assigned to the ligand-to-ligand charge transfer (LLCT; from the HOMO of the $\pi$-orbital of ligand HL to the LUMO of the $\pi$-orbital of ligand Phen). This calculation result is in good agreement with the experimental observations.

\section{4. Solid State UV/Vis Diffuse Reflectance Spectroscopy}

To investigate the semiconductive properties of the title complex, the solid-state UV/Vis diffuse reflectance spectra of powder sample of the title complex was measured at room temperature, using barium sulfate as the reference for $100 \%$ reflectivity. After measuring the solid-state diffuse reflectance spectra, the data was treated with the Kubelka-Munk function that is known as $\alpha / S=(1-R)^{2} /(2 R)$. With regard to this function, the parameter $a$ means the absorption coefficient, $S$ means the scattering coefficient, and $R$ means the reflectance, which is actually wavelength independent when the size of the particle is larger than $5 \mu \mathrm{m}$. From the $\alpha / S$ vs. energy gap diagram, we can obtain the value the optical band gap, which can be extrapolated from the linear portion of the absorption edges. The solid-state UVVis diffuse reflectance spectrum reveals that the complex has a wide optical energy band gap of $3.22 \mathrm{eV}$, as shown in Fig. 8. As a result, the complex is a possible candidate for wide band gap semiconductors. The energy band gap of $3.22 \mathrm{eV}$ of the complex is obviously larger than those of reported organic semiconductors, ${ }^{39-41}$ which are well known as highly efficient band gap photovoltaic materials.

\section{Conclusions}

In summary, a novel zinc complex with mixed ligands was prepared by using a hydrothermal method. The crystal structure of title complex shows that it is a mononuclear isolated structure of the orthorhombic $\mathrm{Pbca}$ spatial system, and a three-dimensional superstructure was constructed by intermolecular hydrogen bonds and intermolecular $\pi \cdots \pi$ interactions. The title complex displays blue purple light photoluminescence, which is due to the ligand-to-ligand charge transfer (LLCT; from the HOMO of the HL to the LUMO of the Phen) as shown by the TDDFT calculation. Solid-state UV/Vis diffuse reflectance spec-
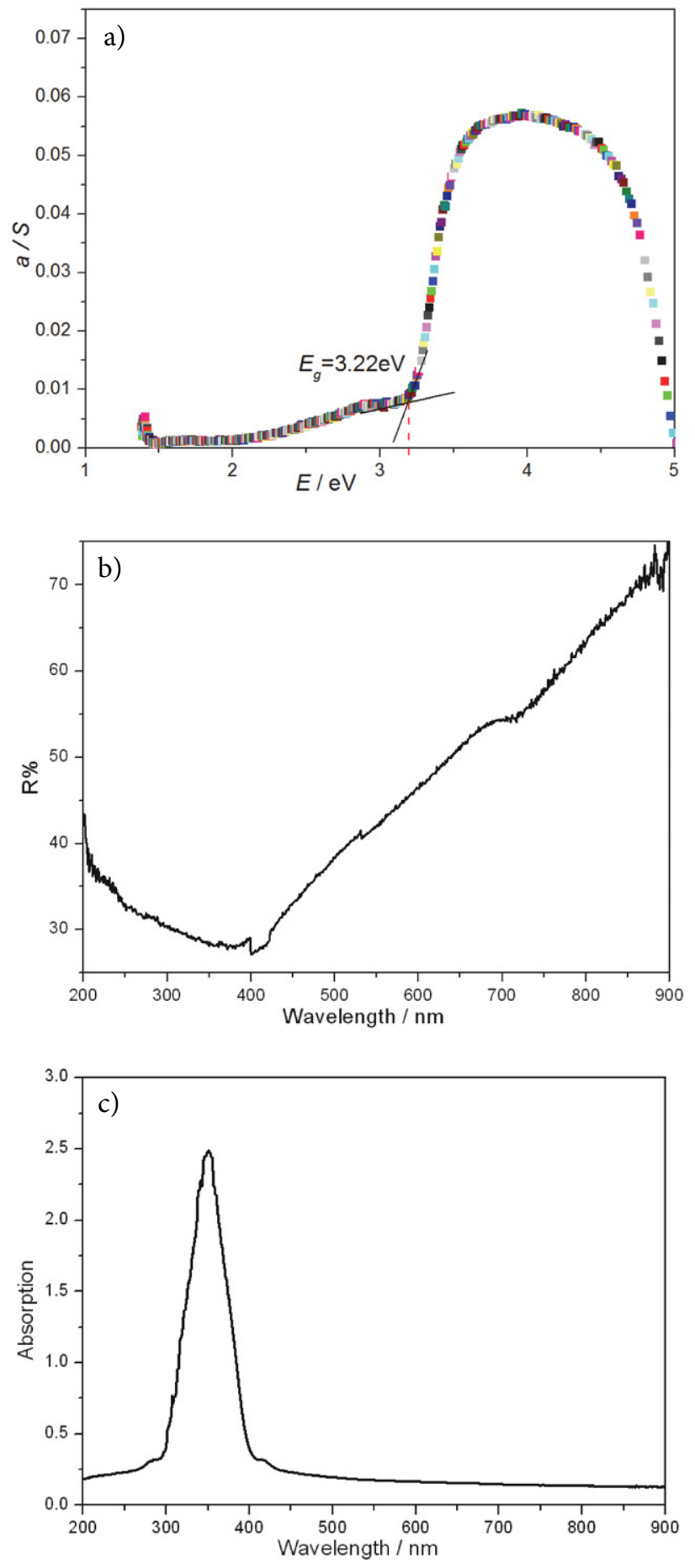

Fig. 8. (a) the solid-state UV-Vis diffuse reflectance spectrum of the title complex; (b) normal UV-vis diffuse reflectance spectra; (c) normal UV-vis absorption spectra measured in DMF solution.

troscopy measurements reveal that the title complex is a candidate used for wide optical band gap organic semiconductors. Our interest is to synthesize more transition metal complexes containing hydroxyquinoline carboxylates and to reveal the intrinsic relationship among the synthesis methods, crystal structures and properties. 


\section{Acknowledgements}

This work was supported by the NSF of China (51363009), Jiangxi Provincial Department of Education's Item of Science and Technology (GJJ190550), Doctoral Research Startup Foundation of Jinggangshan University (JZB1905), and Natural Science Foundation Project of Jinggangshan University (JZ1901).

\section{Appendix A. Supplementary Material}

Crystallographic data for the structural analysis have been deposited with the Cambridge Crystallographic Data Centre, CCDC No. 1913492 for the title complex. Copies of this information may be obtained free of charge from the Director, CCDC, 12 Union Road, Cambridge, CBZ 1EZ, UK (Fax: +44-1223-336033; email: deposit@ccdc. cam.ac.uk or http://www.ccdc.cam.ac.uk).

\section{References}

1. W. H. Zhao, V. Ferro, M. V. Baker, Coord. Chem. Rev. 2017, 339, 1-16. DOI:10.1016/j.ccr.2017.03.005

2. M. Hu, X. Z. Ai, Z. M. Wang, Z. J. Zhang, H. L. Chong, W. M. Zhang, J. Lin, H. H. Yang, B. G. Xing, Nano Res. 2018, 11, 5474-5498. DOI:10.1007/s12274-018-2138-1

3. H. J. Chen, G. Y. Lyu, Y. F. Yue, T. W. Wang, D. P. Li, H. Shi, J. N. Xing, J. Y. Shao, R. Zhang, J. Liu, J. Mater. Chem. C 2019, 7, 7249-7258. DOI:10.1039/C9TC01520E

4. L. H. Abdel-Rahman, A. M. Abu-Dief, R. M. Shehata, F. M. Atlam, Appl. Organomet. Chem. 2019, 33, E4699-4700. DOI:10.1002/aoc.4699

5. D. Lionetti, V. W. Day, J. D. Blakemore, Dalton Trans.2017, 46, 11779-11789. DOI:10.1039/C7DT02577G

6. X. Yang, Q. Zhang, H. Peng, Z. Zuo, D. Yuan, Y. Chen, Q. Chen, G. Chen, Z. Niu, G. Li, Acta Chim. Slov. 2019, 66, 378384. DOI:10.17344/acsi.2018.4876

7. T. Husch, L. Freitaq, M. Reiher, J. Chem. Theory Comput. 2018, 14, 2456-2468. DOI:10.1021/acs.jctc.8b00061

8. W. Lin, W. Chen, H. Kuang, H. Luo, Acta Chim. Slov. 2018, 65, 1008-1013. DOI:10.17344/acsi.2017.4833

9. J. Hou, X. Wang, D. Fu, C. Ko, Y. Chen, Y. Sun, K. X. Wang, K. Dong, S. Tongay, J. Yao, K. Liu, J. Wu, Small 2016, 12, 39763984. DOI:10.1002/smll.201601021

10. K. M. Mccreary, M. Currie, A. T. Hanbicki, H. J. Chuang, B. T. Jonker, ACS Nano. 2018, 11, 7988-7994.

DOI:10.1021/acsnano.7b02554

11. X. D. Ma, B. T. Diroll, W. Cho, I. Fedin, R. D. Schaller, D. V. Talapin, G.-P. Wiederecht, Nano Lett. 2018, 18, 4647-4652. DOI:10.1021/acs.nanolett.8b00347

12. L. Z. Lin, Q. X. Zhong, J. T. Hong, H. L. Chen, W. T. Chen, Inorg. Acta. 2018, 479, 30-35. DOI:10.1016/j.ica.2018.04.039

13. M. Hamer, J. Zultak, A. V. Tyurnina, D. Terry, A. Barinov, A. Garrner, J. Donoghue, A. P. Rooney, V. Kandyba, A. Giampietri, A. J. Graham, N. R. Wilson, Mater. Science 2019, 13, 2136-2142. DOI: 10.1021/acsnano.8b08726.
14. T. Dietl, H. Ohno, F. Matsukura, J. Cibert, D. Ferrand, Science 2000, 287, 1019-1022. DOI:10.1126/science.287.5455.1019

15. W. K. Hyoun, J. K. Yong, M. Ali, Y. K. Sung, S. K. Myung, H.-B. Jae, S. K. Sang, Sensor. Acturat. B:Chem. 2017, 249, 590-601. DOI: $10.1016 /$ j.snb.2017.03.149.

16. K. Makoto, S. Tohru, H. Yukiko, S. Katsuaki, A. Yoshio, Sci. Rep. 2018, 8, 10839. DOI: 10.1038/s41598-018-27953-6.

17. J. G. Kang, K. Taekim, S. Piljeon, A. Facchetti, J. Kim, S. K. Park, RSC Adv. 2019, 9, 6193-6198.

DOI:10.1039/C8RA09917K

18. X. G. Yi, Z. X. Zhang, W. T. Chen, L. Z. Lin, H. L. Chen, J. Solid State Chem. 2018, 266, 16-22.

DOI:10.1016/j.jssc.2018.07.004

19. D. L. Reger, A. Debreczeni, M. D. Smith, Inorg. Chem. 2011, 50, 11754-11764. DOI:10.1021/ic201830h

20. Y. F. Wu, S. Zhao, H. X. Na, P. Y. Yang, H. B. Xu, Y. X. Zhang, Y. L. Chen, M. H. Zeng, Inorg. Chem. 2018, 57, 12683-12689. DOI:10.1021/acs.inorgchem.8b01841

21. S. Tripathi, S. Sachan, G. Anantharaman, Polyhedron 2016, 119, 55-70. DOI:10.1016/j.poly.2016.08.009

22. D. Dhara, P. Kalita, S. Mondal, R. S. Narayanan, K. R. Mote, V. Huch, M. Zimmer, C. B. Yildiz, D. Scheschkewitz, V. Chandrasekhar, A. Jana, Chem. Sci. 2018, 9, 4235-4243. DOI:10.1039/C8SC00348C

23. X. G. Yi, Y. Z. Liu, X. N. Fang, X. Y. Zhou, Y. X. Li, Chinese Struct. Chem. 2019, 38, 325-330.

DOI:10.14102/j.cnki.0254-5861.2011-2065.

24. Rigaku, CrystalClear Version 1.35, Rigaku Corporation, 2002.

25. O. V. Dolomanov, L. J. Bourhis, R. J. Gildea, J. Appl. Cryst.2009, 42, 339-341. DOI:10.1107/S0021889808042726

26. G. M. Sheldrick, Acta Cryst. A 2015, 71, 3-8. DOI:10.1107/S2053229614024218

27. G. M. Sheldrick, Acta Cryst. C 2015, 71, 3-8. DOI:10.1107/S2053229614024218

28. I. D. Brown, D. Altermat, Acta Cryst. B 1985, 41, 240-244. DOI:10.1107/S0108768185002051

29. L. Tian, N. Yang, G. Zhao, Inorg. Chem. Commun. 2010, 13, 1497-1500. DOI:10.1016/j.inoche.2010.08.026

30. O. Kozachuk, K. Khaletskaya, M. Halbherr, Eurjin. Org. Chem. 2012, 10, 1688-1695. DOI:10.1002/ejic.201101295

31. G. Gheno, M. Bortoluzzi, R. Ganzerla, F. Enrichi, J. Lumin. 2014, 145, 963-969. DOI:10.1016/j.jlumin.2013.09.027

32. S. S. Zhang, H. F. Su, Z. Wang, X. P. Wang, W. X. Chen, Q. Q. Zhao, C. H. Tung, D. Sun, L. S. Zheng, Chem. Eur. J. 2018, 24, 1998-2003. DOI:10.1002/chem.201705264

33. Y. Wang, Y. Y. Li, J. Han, X. Tang, L. Ni, L. Wang, RSC Adv. 2016, 6, 82309-82320. DOI:10.1039/C6RA16327K

34. F. Q. Huang, K. Mitchell, J. A. Ibers, Inorg. Chem. 2001, 40, 5123-5126. DOI:10.1021/ic0104353

35. M. D. Allendorf, C. A. Bauer, R. K. Bhakta, R. J. T. Houk, Chem. Soc. Rev. 2009, 38, 1330-1352.

DOI: $10.1039 / \mathrm{b} 802352 \mathrm{~m}$

36. A. D. Becke, J. Chem. Phys. 1993, 98, 5648-5652. DOI:10.1063/1.464913

37. C. Lee, W. Yang, R. G. Parr, Phys. Rev. B 1988, 37, 785-789. DOI:10.1103/PhysRevB.37.785 
38. M. J. Frish, et al., Gaussian 09, Revision A.02, Gausian, Inc., Wallingford CT, 2009.

39. R. Agneeswari, M. Kong, J. Lee, J.H. Kwon, V. Tamilavan, S.S. Park, S.H. Park, Y. Jin, Mol. Cryst. Liq. Cryst. 2019, 685, 29-39. DOI:10.1080/15421406.2019.1645458
40. H.-M. Kuang, J.-G. Huang, L.-Z. Lin, Q.-X. Zhong, W.-T. Chen, Inorg. Chim. Acta 2019, 489, 48-53.

DOI:10.1016/j.ica.2019.02.006

41. Q. Luo, H. Luo, H. Kuang, W. Chen, Y. Wen, J. Solid State Chem. 2019, 270, 200-204. DOI:10.1016/j.jssc.2018.09.040

\section{Povzetek}

$\mathrm{S}$ hidrotermalno sintezo smo pripravili nov enojedrni cinkov kompleks $\left[\mathrm{ZnL}(\mathrm{Phen})\left(\mathrm{H}_{2} \mathrm{O}\right)\right] \cdot \mathrm{H}_{2} \mathrm{O}$, ki vsebuje liganda Phen (Phen = 1,10-fenantrolin) in 3-hidroksi-2-metilkinolin-4-karboksilno kislino (HL). Določili smo strukturo z monokristalno rentgensko difrakcijo. Kompleks kristalizira v ortorombskem kristalnem sistemu in tvori enojedrne enote. Molekule so povezane preko vodikovih vezi in $\pi \cdots \pi$ interakciji in tvorijo tridimenzionalno $(3 D)$ supramolekularno strukturo. Pri fluorescenci je razviden širok emisijski pas v vijolično-modrem območju. Izračuni z uporabo časovno odvisne teorije gostotnostnega funkcionala (TDDFT) kažejo, da lahko emisijo pripišemo prenosu naboja ligand-ligand (LLCT). Difuzna reflektanca v trdnem stanju kaže na širok optični pasovni razmik. 